\title{
A Study on the Using Motivation of Zu'an Culture in Chinese Middle School
}

\author{
Yuting Dong, ${ }^{1, *}$ and Zilin Zhang ${ }^{2}$ \\ 1967, East Anning Road, Education College, Northwest Normal University, Lanzhou, China \\ ${ }^{1}$ School of Energy and Mechanical Engineering, Jiangxi University of Science and Technology, Nanchang, China \\ 2999, Wolong Road, General Office, Jiangxi Information Center, Nanchang China \\ *Yuting Dong. Email:517762293@qq.com
}

\begin{abstract}
July 11, 2020, a report in Bimonthly Talk magazine entitled "It's Time to Stop the Invasion of Zu'an Cultural Circle into Campus". It has aroused widespread concern and heated discussion in the society. This article through the qualitative research case study method from sociology, psychology and other perspectives. Semi-structured interviews were conducted among 25 middle school students. Encoding the interview case text by Nvivo11, Fifteen categories, five main categories and one core category are extracted. The study found that the use of Zu'an culture by middle school students is essentially a process of social adaptation. Middle school students form identity symbols, meet the Attribution Requirement and esteem needs,do representation of power,maintain a state of pleasure through the use of Zu'an culture. However, in the face of the contradiction between the adaptation instinct and the construction of a civilized and harmonious society, We should make full use of technical means.To create a kind of cultural soft environment for good. By changing the object of adaptation, imperceptibly make this social adaptation instinct spontaneous change to a better and more beautiful direction.
\end{abstract}

Keywords: Zu'an culture, Cultural soft environment, Social Adaptation.

\section{INTRODUCTION}

Recently, The Outgoing and Invasion of Zuan Culture into School has aroused widespread concern and heated discussion in the society. Some researchers believe that the essence of Zu'an culture is the youth subculture with the network export as the core. Others think that it is a kind of Internet language drift that tries to scold people and greets each other's ancestors at every turn;Guangming Daily published an article entitled "Zu'an City is not a cultural stagnation," saying that those profanities that look more advanced and powerful are not sharp;It's not a beautiful language, it's just a little skill of combining words. Of course, that is not to mention what culture, but the shallow expression of mouth addiction; China Youth Daily, in an article entitled "Not all subcultures deserve respect and tolerance", believes that in the form of dirty words, Zu'an culture breeds in every corner of net space, violates social order, good customs and morality, even infringes on personal rights, and destroys the purity and elegance of language expression. Such a culture makes people feel sick, and it is also a cancer that should be cut and clean in the internet public opinion field.
26 August 2020,The Ministry of Education and other six departments jointly issued a notice on the joint development of minors'network environment special rectification action, which In the task of work, it is clearly proposed to rectify the bad network social behavior and increase the black boundary.Zu'an culture, etc. Involving minors bad network social behavior and governance efforts.

Zu'an culture is mainly expressed in the form of Zu'an language, which has been labeled as a dirty word. Review of domestic and foreign research on dirty words, these studies are mainly refer to the definition, classification, function, motivation and viewpoints of swear words from the perspectives of sociology, ethics, pragmatics, psychology, etc..

By definition, Jay Define profanity as words that are interpreted as insulting, based on strong emotions, offensive and destructive expressions, These words have a strong emotional expression, to cause great destruction within the subject[1].Different researchers divided dirty words into two types that are related to personal psychological experience of business transformation and interpersonal relationship from the use motivation, use 
way, use efficacy and other different angles[2];There are also five categories: descriptive, habitual, abusive, emphatic, and hysterical[3];Ruth divided dirty words into three categories: venting, habitual and offensive[4].In the study of the differences in the use of dirty words, Lakoff think there is a gender difference in the use of dirty words, Men tend to use strong dirty words, while women tend to use more mild dirty words. Women are subject to more supervision and pressure than men when they use dirty words[5][6].Zhang Wanli and others have found that there are differences between Chinese and Western cultural regions in dirty words.[6]Ruth believe the motivation for using dirty words can be roughly categorized into three situation: Abreaction, Curse; communication. Some empirical studies have shown that the generation of online and real dirty words is closely related to personal social environmental factors, personal awareness of dirty words and results expectations[7]; The reasons why the teenagers use the Internet dirty words are influenced by the blurring of the boundary of the Internet reality, the subculture of emotional expression, personal socialization and the loss of sensitivity to the internet dirty words[8]; The influence of peers in the transmission of bad network language is strong[9].There are also different views on profanity. Hen Rudong once said in the book of language ethics.Foul language not only affects interpersonal communication and cooperation,cause harm to society and others, it also degrades a person's character and is unacceptable by public opinion and morality[10].However, some researchers believe that speaking should pay attention to the appropriateness of the language is based on the specific context. The dirty or not dirty of dirty words depends on the context and the appropriateness under the context [11].Chen Guanglei, in his book Decent: The basic conventions of pragmatics points out that Cultural rules that require speech to be practical, That is to say it is correct and appropriate in the expression of social interpersonal relationship. This is about the pragmatic Appropriateness [12].

Other researchers believe that from a social psychological point of view, dirty words can help people vent their anger and ease their emotions, and in certain situations, dirty words can help individuals gain a sense of group identity and obtain necessary social resources.However, over the years, the views and evaluation of dirty words have not yet reached a consensus, and dirty words still appear in a variety of identification, and there is a growing trend. It runs counter to the construction of a civilized and harmonious society. This study aims to deeply explore the essential motivation of Chinese middle school students using $\mathrm{Zu}$ 'an culture.

\section{RESEARCH METHODS AND DATA SOURCES}

\subsection{Research Methodology}

The case selection in this study follows the principle of random sampling. In this study, 25 middle school students from 4 middle schools of different levels in Gansu Province were interviewed. Interview with the introduction of $\mathrm{Zu}$ 'an culture to determine the direction of interview, According to the relevant themes that automatically emerge from the field for questioning and dialogue. Then the interview data were analyzed by Nvivo11 for word frequency statistics and coding analysis.

Through this kind of statistics, we analyze and count 25 case texts. The top 50 most frequently used words are listed in Table 1.From the graph we find that words such as culture ,schoolmate, game, LOL, politeness, harm, pressure, relationship, bad language and so on are high frequency words. It can be seen that the interviewees concerned about the ways, the reasons and the consequences.

Table 1. Statistical table of case word frequency

\begin{tabular}{|c|c|c|c|c|c|c|c|}
\hline Word & Length & Count & Weighted & Word & Length & Count & Weighted \\
\hline culture & 2 & 92 & 2.05 & home & 2 & 11 & 0.24 \\
\hline LOL & 2 & 84 & 1.86 & chat & 2 & 12 & 0.22 \\
\hline classmate & 2 & 67 & 1.49 & abreact & 2 & 9 & 0.20 \\
\hline game & 2 & 55 & 1.22 & attack & 2 & 9 & 0.20 \\
\hline politiness & 2 & 40 & 0.89 & manner & 2 & 9 & 0.20 \\
\hline harm & 2 & 37 & 0.82 & boy & 2 & 9 & 0.20 \\
\hline pressure & 2 & 37 & 0.82 & habit & 2 & 8 & 0.18 \\
\hline usually & 2 & 32 & 0.71 & out going & 2 & 8 & 0.18 \\
\hline aside & 2 & 28 & 0.62 & emotion & 2 & 8 & 0.18 \\
\hline teacher & 2 & 26 & 0.58 & king & 2 & 8 & 0.18 \\
\hline school & 2 & 25 & 0.56 & heard & 2 & 7 & 0.16 \\
\hline language & 2 & 19 & 0.42 & parents & 2 & 7 & 0.16 \\
\hline girl & 2 & 16 & 0.36 & anger & 2 & 7 & 0.16 \\
\hline joke & 2 & 16 & 0.36 & integrate & 2 & 7 & 0.16 \\
\hline friend & 3 & 16 & 0.36 & frequent & 2 & 7 & 0.16 \\
\hline language & 2 & 15 & 0.33 & fashion & 2 & 6 & 0.13 \\
\hline internet & 2 & 14 & 0.31 & glory & 2 & 6 & 0.13 \\
\hline situation & 2 & 13 & 0.29 & harmony & 2 & 6 & 0.13 \\
\hline everyday & 2 & 13 & 0.29 & ridicule & 2 & 6 & 0.13 \\
\hline character & 2 & 12 & 0.27 & back & 2 & 6 & 0.13 \\
\hline contact & 2 & 12 & 0.27 & close & 2 & 5 & 0.11 \\
\hline civilization & 2 & 12 & 0.27 & mind & 2 & 5 & 0.11 \\
\hline
\end{tabular}


Table 2. Sample basic information

\begin{tabular}{|c|c|c|c|c|c|c|c|}
\hline Number & Gender & Age & $\begin{array}{l}\text { Player of } \\
\mathrm{LOL}(\mathrm{Y} / \mathrm{N})\end{array}$ & $\begin{array}{c}\text { Know Zu'an } \\
\text { Culture } \\
(\mathrm{Y} / \mathrm{N})\end{array}$ & $\begin{array}{c}\text { Only child } \\
(\mathrm{Y} / \mathrm{N})\end{array}$ & Grade & Source \\
\hline A01 & male & 14 & $\mathbf{N}$ & $\mathrm{Y}$ & $\mathrm{N}$ & 8 & A middle school \\
\hline $\mathrm{A02}$ & male & 15 & $\mathbf{N}$ & Y & $\mathrm{N}$ & 8 & A middle school \\
\hline $\mathrm{A} 03$ & male & 14 & $\mathbf{N}$ & $Y$ & $\mathrm{Y}$ & 8 & A middle school \\
\hline A04 & male & 14 & $\mathbf{Y}$ & Y & $\mathrm{N}$ & 8 & A middle school \\
\hline $\mathrm{A} 05$ & male & 15 & $\mathrm{Y}$ & $\mathrm{Y}$ & $\mathrm{Y}$ & 8 & A middle school \\
\hline A06 & male & 14 & $\mathbf{Y}$ & $Y$ & $\mathrm{~N}$ & 8 & A middle school \\
\hline A07 & male & 14 & $\mathbf{Y}$ & $Y$ & $\mathrm{~N}$ & 8 & A middle school \\
\hline B08 & male & 17 & $\mathbf{N}$ & $Y$ & $\mathrm{Y}$ & 11 & B high_school \\
\hline B09 & male & 17 & $\mathbf{N}$ & $\mathrm{Y}$ & $\mathrm{N}$ & 11 & B high school \\
\hline B10 & male & 18 & Y & Y & $\mathrm{N}$ & 11 & B high school \\
\hline B11 & male & 17 & $\mathbf{N}$ & Y & $\mathrm{N}$ & 11 & B high school \\
\hline B12 & male & 17 & $\mathrm{Y}$ & $\mathrm{Y}$ & $\mathrm{N}$ & 11 & B high school \\
\hline B13 & male & 16 & $\mathbf{N}$ & $Y$ & $\mathrm{Y}$ & 11 & B high school \\
\hline C14 & female & 16 & $\mathbf{Y}$ & $Y$ & $\mathrm{~N}$ & 10 & C high school \\
\hline C15 & male & 17 & $\mathbf{Y}$ & $Y$ & $\mathrm{Y}$ & 10 & Chigh school \\
\hline C16 & male & 16 & $\mathbf{N}$ & $Y$ & $\mathrm{~N}$ & 10 & Chigh_school \\
\hline $\mathrm{C} 17$ & male & 17 & $\mathbf{N}$ & $Y$ & $\mathrm{~N}$ & 10 & C high school \\
\hline $\mathrm{C} 18$ & male & 16 & $\mathbf{N}$ & $\mathrm{Y}$ & $\mathrm{Y}$ & 10 & Chigh_school \\
\hline $\mathrm{C19}$ & male & 16 & $\mathrm{Y}$ & $\mathrm{Y}$ & $\mathrm{N}$ & 10 & C high school \\
\hline D20 & male & 13 & $\mathrm{Y}$ & $Y$ & $\mathrm{Y}$ & 7 & $\mathrm{D}$ middle school \\
\hline D21 & male & 13 & $\mathbf{N}$ & $\mathrm{Y}$ & $\mathrm{N}$ & 7 & $\mathrm{D}$ middle school \\
\hline D22 & male & 13 & $\mathbf{N}$ & Y & $\mathrm{N}$ & 7 & $\mathrm{D}$ middle school \\
\hline $\mathrm{D} 23$ & female & 13 & $\mathbf{N}$ & Y & $\mathrm{Y}$ & 7 & $\mathrm{D}$ middle school \\
\hline D24 & female & 14 & $\mathbf{N}$ & $\mathrm{Y}$ & $\mathrm{Y}$ & 7 & $\mathrm{D}$ middle school \\
\hline D25 & female & 13 & Y & Y & Y & 7 & D middle school \\
\hline
\end{tabular}

\subsection{Data Sources}

The data of this paper is mainly based on the interview data of 25 middle school students from 4 different levels. The basic information of the case is shown in Table 2.

\section{ENCODING}

\subsection{Open Coding}

Conceptualization. In strict accordance with the principle of close to the material, read and analyze the original text sentence by sentence, and pay attention to the use of the original code in coding. It begins to categorize after coding, multiple comparison and correction. According to semantics and relationship of logic to determine the meaning and attributes of a concept, to abstract name for various categories. There are 15 categories, such as ccommunication means, integration means, satire and against, against the discipline, rebel against authority, emotion abreaction, against cognitive dissonance, seek for interest, imitating, pursue uniqueness, according to close, protect themselves and against, emotion abreaction, against cognitive dissonance, seek for interest, ssocial recognition, moral constraint, punitive measure. See Table 3, column 3 .

\subsection{Axial Coding}

The main task of axial coding is to discover and establish the relationships between categories and to show the organic relationship between the various parts of the data. There are five main categories, which are esteem needs, identity symbol, power characterization, Keep the joy, social environment.

\subsection{Selective Coding}

Selective coding is to select a core category from all categories. Other categories become subsidiary category, and then through an integrating scheme or story line integrate all kinds of category attribute assumptions of theoretical elements. In-depth analysis of 5 Axial codings, It is found that the need for esteem, identity symbol, Power characterization, Keep the joy and social environment are all due to the individual for Keep adapting social. They can all be covered by the motivation of social adaptation. Therefore, the main 
reason for middle school students to use the $\mathrm{Zu}$ 'an culture is social adaptation. See Table 3, column 1.

Table 3. Three-level coding table

\begin{tabular}{|c|c|c|}
\hline $\begin{array}{c}\text { Level 3 coding: } \\
\text { Selective Coding }\end{array}$ & $\begin{array}{c}\text { Level 2 coding: } \\
\text { Axial Coding }\end{array}$ & $\begin{array}{c}\text { Level 1 coding: } \\
\text { Open Coding }\end{array}$ \\
\hline \multirow{4}{*}{$\begin{array}{c}\text { Social } \\
\text { Adaptation }\end{array}$} & Esteem Needs & Protect themselves and against \\
\cline { 2 - 3 } & Identity Symbol & $\begin{array}{c}\text { Imitating,Pursue } \\
\text { uniqueness,According to Close }\end{array}$ \\
\cline { 2 - 3 } & $\begin{array}{c}\text { Communicationmeans,Integration } \\
\text { means,Satire and against,Against the } \\
\text { discipline,Rebel against authority }\end{array}$ \\
\cline { 2 - 3 } & Keep the Joy & $\begin{array}{c}\text { Emotional abreaction,Against } \\
\text { cognitive dissonance,Seek for interest }\end{array}$ \\
\cline { 2 - 3 } & Social Environment & $\begin{array}{c}\text { Social Recognition,Moral Restraint, } \\
\text { Punitive measures }\end{array}$ \\
\hline
\end{tabular}

\section{RESEARCH FINDINGS}

The motivation of middle school students to use $\mathrm{Zu}$ 'an culture is analyzed deeply from the Macroscopic perspective in this study. Fifteen categories were extracted from the interview data, such as communication means, integration means, satire and against, against the discipline, rebel against authority, emotion abreaction, against cognitive dissonance, seek for interest, imitating, pursue uniqueness, according to close, protect themselves and against, emotion abreaction, against cognitive dissonance, seek for interest, social recognition, moral constraint, punitive measure. Extract five main categories which are esteem need, identity symbol, Power characterization, Keep the joy and social environment. Finally, a core category which is social adaptation is extracted. And on this basis to build a use motivation model of Zu'an culture, see Figure 1.The study found that middle school students using Zu'an culture is essentially a process of social adaptation, it is an instinct.

\section{CONCLUSION AND DISCUSSION}

Based on the semi-structured interviews, this study conducted a three-level coding and analysis of their own materials. Part of the conclusions of the first level coding and the second level coding are the same as those of previous studies on dirty words. But now in the process of judging the culture of obstruction, people often do not study it deeply, and directly label it as violating social order, good morality and morality. After analysis, it found that behind the appearance of behavior is an instinct of social adaptation.

Freud first systematically discussed the characteristics of instinct in his instinct and Its Changes published in 1915. One of the is that every instinct has a source, and another characteristic is that every instinct has a purpose. The roots of instinct, the needs and urges that come from within the body. A need and impulse embodied in the human body an organ of the excitation process, and this excitation process must be stored in the body's energy release. The purpose of instinct is to eliminate the source of the instinctive stimulus and to satisfy the needs of the body or to relieve the resulting excitement and tension process. So instinctive behavior is not a temporary shock, but a fixed force, but from its internal visible, cannot be used to escape against it. It could only by appropriate changes in the internal incentives. We assume that The interest behind the tension caused by the needs of the ID is the instinct. The interest behind the tension caused by the needs of the ID is instinct[13].Instinct is the ultimate cause of all activities, but its essence is conservative, no matter what state the organism reaches, It have a tendency that As soon as that state disappears, it will be established again [14].We can assume that it's an instinct to be disturbed in a certain state that things have achieved, to produce, to recreate that state, and to produce a state that we can call the phenomenon of forced repetition [15].

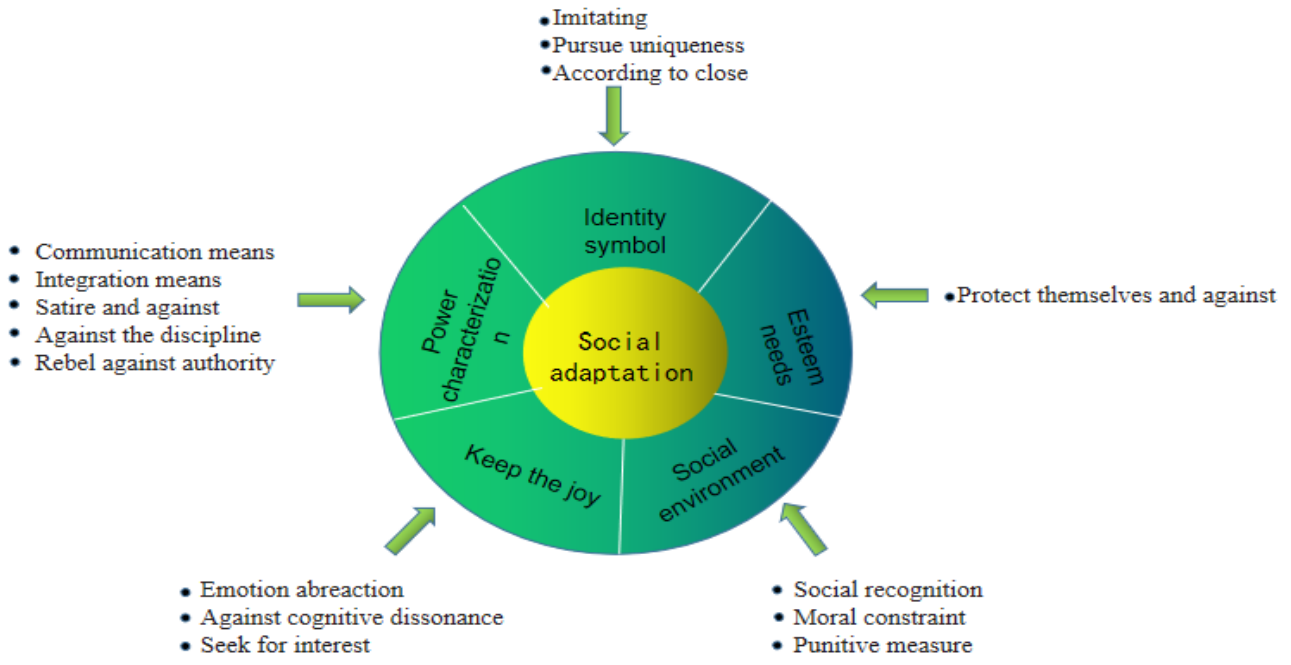

Figure 1 The use motivation model of $\mathrm{Zu}$ 'an culture 
When under attack, the need for respect, symbols of identity, symbols of power, and the maintenance of a pleasant social environment, Middle school students feel the inner need and impulse, Need and impulse will then produce the process of excitement, and activate this social adaptation instinct of middle school students, The instinct of social adaptation ensures that this exciting process must release the energy stored in the body, $\mathrm{Zu}$ 'an culture is such a release. The main function and purpose of this release is to meet the internal needs of middle school students and the impact, so that middle school students return to the original state, which is the repetition of instinct. Since the stimulus cannot come from within, it cannot be used in a simple way to escape and action, can only be properly eliminated or change this internal stimulus. How to properly eliminate or change this internal stimulus?

We should make full use of technical means to create a good cultural soft environment. The so-called soft environment is a concept relative to the hard environment. It refers to the sum of external factors and conditions beyond material conditions, such as policies, culture, systems, laws, and ideological concept. In the existing environment, these factors are reflected in the mechanism., which isrelative to Geographical conditions, resources, infrastructure, basic conditions and other hardware in terms of ideas, cultural atmosphere, institutional mechanisms, policies and regulations and government administrative capacity, level and attitude. We should keep pace with the times, Make good use of scientific and technological means, Increasing investment and construction of soft environment, such as philosophical education, moral education, music education, art education, aesthetic education, etiquette education and other relevant soft environment construction. Finally, it is formed form a good cultural soft environment. In order to make this environment in accordance with the ego and the superego, avoid provoking instinctive stimuli. In this way, the problem of Zu'an culture would besolved.

\section{REFERENCES}

[1] Jay, T., \& Janschewitz, K. (2008). The pragmatics of swearing. Journal of Politeness Research, 4,267288.

[2] Montagu,A.(1967).The anatomy swearing.London:Rapp and Whiting.
[3] .Pinker,S.(2007).The stuff of thought: Language as a win- dow into human nature.New York:Penguin.

[4] Ruth Wajnryb.Language most foul [M]. Allen \& Unwin, 2005.

[5] Popp,D.,Donovan,R.A.,Crawford,M.,Marsh,K.L.,\& Peele,M.(2003).Gender,ethnicity,and speech stereotypes. Sex Roles, 48(7/8), 317-325.

[6] Zhang Wanli \& HuZhijun.(2010).Diversity Psychology Analysis about Abusive Language Phenomenon and the Study Approach from Cultural Psychology.Journal of

Gansu Normal Colleges (01), 140-142.

[7] Chen Anfan .(2015). Empirical Research on the Occurrence mechanism of Network profanity Speech Behavior -- Based on Bandura's Social cognition theory.Southeast Communication (08), 73-78.

[8] Li Changjian,Shen Luyi \& Dan Sichen.(2019).An empirical Study on the motivation of the contemporary youth group to use "Network profanity". Southeast Communication (09), 96-99.

[9] Cai Zhiyu, Hu Qi,Zhang Wei \& Zhang Jiajun.(2020).Analysis on the current situation of the use and dissemination of teenagers' bad Network language. Radio\&TV Journal (06),156158.

[10]Chen Rudong. Linguistic ethics $[\mathrm{M}]$.Beijing: Peking University Press, 2001.

[11]Zhang Faxiang.(2007).The Appropriateness of Dirty Words Under Special Linguistic Situations.Journal of Henan University of Science and Technology(Social Science) (05),65-67.

[12] Chen Guanglei. Appropriateness: The Basic Rules of Pragmatics [M]. Tianjin: Tianjin Education Press, 1986.

[13][14][15] The Selected Works of Sigmund Freud. Wang Fengyan \& GuoBenyu [M]. //CheWenbo.SigmundFreud(05).Changchun: Changchun Publishing House, 1986:99. 